\title{
Microalbuminuria versus Brain Natriuretic Peptide in Cardiac Hypertrophy of Hypertensive Rats
}

\author{
Y. SALIBA ${ }^{1}$, E. CHOUERY ${ }^{2}$, A. MÉGARBANÉ ${ }^{2}$, H. JABBOUR ${ }^{3}$, N. FARÈS ${ }^{1}$ \\ ${ }^{1}$ Laboratoire de Physiologie et Physiopathologie, Faculté de Médecine, Université Saint Joseph, \\ Beyrouth, Liban, ${ }^{2}$ Unité de Génétique Médicale, Faculté de Médecine, Université Saint Joseph, \\ Beyrouth, Liban, ${ }^{3}$ Département d'Anesthésie et de Réanimation, Hôtel-Dieu-de-France, Beyrouth, \\ Liban
}

Received June 1, 2009

Accepted March 26, 2010

On-line June 9, 2010

\section{Summary}

The objective of this study was to assess a possible link between microalbuminuria (MA), a major risk factor of the cardiorenal syndrome and the brain natriuretic peptide (BNP), a marker of cardiac hypertrophy. Two kidney-one clip (2K-1C) renovascular hypertension was induced in 24 male Wistar rats (weighing 220$250 \mathrm{~g}$ ). Rats were randomized into four groups for 8 weeks: Sham, not treated; Bos, treated with bosentan; Cap, treated with captopril; Bos/Cap, treated with both drugs. Blood pressure, plasma BNP and transforming growth factor $\beta 1$ (TGF- $\beta 1$ ) concentrations, microalbuminuria and creatininemia as well as cardiac mass, BNP, a- and $\beta$-myosin heavy chain (MHC) gene expression and kidney histology were determined. Following stenosis, Sham rats developed hypertension $(p<0.001)$, an increase in BNP $(p<0.05)$ and TGF- $\beta 1(p<0.005)$ concentrations, creatinine levels $(p<0.001)$, and urinary albumin $(p<0.001)$. Under drug treatment, decreases in blood pressure $(p<0.001)$, creatinine levels $(p<0.05)$, plasma TGF- $\beta 1(p<0.005)$ and BNP $(p<0.05)$ concentrations, were concomitant with the absence of MA which was significantly correlated with reductions in cardiac mass $(p<0.05)$ and hypertrophy markers (BNP and $\beta$-MHC gene expression) $(p<0.005)$ as well as in renal fibrosis. These findings suggest a potential link between microalbuminuria evolution and BNP as well as a possible effect of microalbuminuria-lowering therapy on halting the progression, or even inducing the regression of cardiac hypertrophy.

\section{Key words}

Microalbuminuria - Brain natriuretic peptide - Hypertension • Cardiac hypertrophy

\section{Corresponding author}

N. Farès, Laboratoire de Physiologie et Physiopathologie, Faculté de Médecine, Université Saint Joseph, rue de Damas, B.P. 11-5076, Riad el Solh, Beyrouth 1107 2180, Liban. Fax: + 9611 421 023. E-mail: nassim.fares@usj.edu.lb

\section{Introduction}

Cardiovascular diseases (CVD) related factors are responsible for the death of more than $50 \%$ of patients with chronic kidney disease (CKD) (USRDS 2008) or end-stage renal disease (ESRD) (Keith et al. 2004). Therefore, it is not surprising that 30 to $50 \%$ of patients with congestive heart failure (CHF) exhibit a disruption of the glomerular filtration (McAlister et al. 2004). The term cardiorenal syndrome (CRS) has been increasingly used without a consistent well-accepted definition; it is manifested by renal failure, microalbuminuria (MA), resistance to diuretics, anemia, and tendency towards hyperkalemia and low systolic blood pressure (SBP). Renal failure leads to a diverse pathophysiologic array including: changes in the process of coagulation and fibrinolysis, endothelial dysfunction, anemia, disorders of the phospho-calcium balance, dysfunction of the renin-angiotensin-aldosterone system (RAAS), abnormal lipid metabolism, left ventricular hypertrophy (LVH) and arrhythmias (McCullough 2002).

The CRS can be classified into five subtypes including a vast array of interrelated derangements and reflecting the bidirectional nature of heart-kidney 
interaction (Ronco et al. 2008). In fact, this interaction is a two-way process: renal dysfunction causes heart problems, and vice versa. Van Dokkum et al. (2004) examined the effects of myocardial infarction on the loss of renal function in unilaterally nephrectomized rats and suggested that heart failure (HF) worsens renal dysfunction, possibly via neurohumoral signals. This mutual interaction justifies the concept of the CRS (Schrier 2006).

Microalbuminuria appears to be a major risk factor of this syndrome. In fact, it is currently considered as a marker of endothelial dysfunction and vascular permeability (McCullough 2007). It is associated with LVH and hypertension; subjects with MA are highly vulnerable to CVD with a high mortality rate (Wachtell et al. 2002).

Although a recent study found a correlation between blood pressure control, MA and BNP (Uno et al. 2008), cardiac hypertrophy was not evaluated, and thus the relationship between MA and cardiac hypertrophy remains not very clear. There are no current studies at the cellular or molecular level which prove the existence of a clear direct relationship between these two entities. It is well established that treatment with angiotensin converting enzyme inhibitors (ACEI) or angiotensin II receptor blockers (ARBs) in $\mathrm{CKD}$, improves renal function and decreases hospitalization risk for a $\mathrm{CHF}$ (Brenner et al. 2001). In addition, in vitro studies in rats have shown that treatment with endothelin receptor blockers (ERBs), especially endothelin type A (ET-A) receptor blockers, modulates the natriuretic peptides gene expression in renovascular hypertension (Bianciotti and De Bold 2001) and prevents left ventricular hypertrophy and the re-expression of the $\beta$-MHC and atrial natriuretic peptide genes on day 2 in the same $2 \mathrm{~K}-1 \mathrm{C}$ model, independently of blood pressure effects (Ehmke et al. 1999).

Based on these facts, we used a non-selective ERB and an ACEI as pharmacological tools to treat $2 \mathrm{~K}-1 \mathrm{C}$ adult hypertensive rats, in order to assess a possible link between microalbuminuria evolution, a major risk factor of the CRS, and BNP, a marker of cardiac hypertrophy.

\section{Materials and Methods}

The protocols of the present study were designed according to the Guiding Principles in the Care and Use of Animals approved by the Council of the American
Physiological Society and were in adherence to the Guide for the Care and Use of Laboratory Animals published by the US National Institutes of Health (NIH Publication no. 85-23, revised 1996).

\section{Animals}

Thirty male Wistar rats (weighing 220-250 g) were obtained from the "Centre d'Elevage R. Janvier" (Le Genest-Saint Isle, France). The animals were housed in individual metal wire metabolic cages with constant temperature $\left(25^{\circ} \mathrm{C}\right)$. A specific air ventilation system assured an efficient flow within the room to keep the level of humidity within the animals' immediate environment at an acceptable level; thus, the relative humidity was within the range of $50 \pm 5 \%$. The rats were exposed to a 12: 12-h light-dark cycle, were fed ordinary rat chow, had free access to tap water and were acclimatized for at least one week under these conditions before the start of the study.

\section{Induction of $2 K-1 C$ hypertension}

During ketamine (Interchemie, Holland) and xylazine (Rotex Medica, Germany) anesthesia (75 and $10 \mathrm{mg} / \mathrm{kg}$, respectively), the right kidney was exposed through a flank incision. The right renal artery was clipped by placing of a rigid U-shaped silver clip (SLSclips, Vitalitec, France) with an internal opening of $0.25 \mathrm{~mm}$. The left kidney was left intact.

\section{Experimental groups}

The operated rats were randomly assigned into four groups of 6 animals: the Bos group treated with the non-selective ERB, bosentan (Actelion, Allschwil, Switzerland); the Cap group treated with the ACEI captopril (Novartis, Switzerland); the Bos/Cap group treated with both drugs and the Sham group which was not subjected to any pharmacological treatment. Treatment began after the establishment of hypertension two weeks after the stenosis. Every morning drugs were given with a small amount of the drinking water $(5 \mathrm{ml})$ to achieve a final consumption of $10 \mathrm{mg} \cdot \mathrm{kg}^{-1} \cdot \mathrm{day}^{-1}$; then each rat was switched back to the tap water as soon as the five milliliters were consumed. The rats were all housed under the same conditions, and since their body weights were comparable throughout the study, the necessary time for the $5 \mathrm{ml}$ consumption was approximately the same for all the rats within the same group. The animals were sacrificed after 8 weeks following the stenosis. The development of cardiac hypertrophy in the Sham group 
was evaluated by comparing the animals' hearts weights to those of the fifth group containing six un-operated untreated control rats; these control animals were also kept in metabolic cages under the same conditions throughout the study, and were eventually sacrificed for the purpose of weighing their hearts to obtain the normal baseline values, and therefore assessing the development of cardiac hypertrophy in the other groups.

\section{Measurements of systolic blood pressure SBP}

SBP was measured, in all the 24 conscious resting rats before clipping, twice daily for one week for the normal baseline values, and once daily during the development of high SBP, using the tail-cuff method (Swislocki et al. 1999, Kubota et al. 2006) with an electrosphygmograph (Model 29 amplifier and sensors, IITC, Woodland Hills, CA). Our measurement system was calibrated weekly using an aneroid sphygmomanometer. Just before blood pressure measurements, rats were placed in acrylic holders (Model 82, IITC). At each time point, two SBP measurements were taken on each animal and averaged. To avoid variations in SBP due to day cycle, all measurements were carried out between 10 and 12 a.m. Preliminary training sessions were performed during one week before starting the experiment.

\section{Measurements of plasma BNP, TGF- $\beta 1$ and creatinine}

During the week before clipping, three blood samples were taken from each of the 24 rats, one each two days, for normal baseline values. After the stenosis, one blood sample was weekly taken from the jugular vein of each rat, till the sacrifice. All blood samples were directly centrifuged at 6000 r.p.m and plasma was kept at $-80{ }^{\circ} \mathrm{C}$ for later measurements. ELISA technique was used for BNP and TGF- $\beta 1$ measurements: BNP-32 (Rat) kit (Peninsula Laboratories, Bachem Group, USA) was used to measure plasma BNP, and Quantikine Mouse/Rat/Porcine/Canine TGF- $\beta 1$ kit (R\&D Systems, USA) for TGF- $\beta 1$ measurement. Moreover, plasma creatinine measurement was based on the reaction of creatinine with alkaline picrate as described by Jaffé (Kit: Biolabo, Maizy, France).

\section{Measurement of urinary albumin}

During the week preceding the clipping, three 24-hour urine samples were collected (once each two days) from each of the 24 rats to obtain normal baseline values.
Then after the stenosis, one weekly sample was collected till the sacrifice on the eighth week. All urine samples were conserved at $-80{ }^{\circ} \mathrm{C}$ for later measurements. The NycoCard U-ALBUMIN kit (AxisShield, Norway) was used to evaluate MA.

\section{Cell dissociation for RNA isolation}

Following the sacrifice, rat hearts were cut off and weighed. Ventricular myocytes were dissociated from the isolated hearts of sham and treated rats by enzymatic digestion as previously described (Farès et al. 1996). Briefly, the rats were injected with 1000 i.u. heparin i.p. (Choay; Sanofi, Gentilly, France) and anaesthetized with the ketamine/xylazine mixture; hearts were quickly removed via thoracotomy and transferred to an ice-cold Tyrode solution. The aorta was cannulated and the heart mounted on a Langendorff apparatus and successively perfused (at $37{ }^{\circ} \mathrm{C}$ ) with the following oxygenated solutions: 5 min with Tyrode solution; $4 \mathrm{~min}$ with a nominally $\mathrm{Ca}^{2+}$-free Tyrode solution, and about 20 min with the same solution supplemented with $0.05 \%$ collagenase (type II, Worthington), $0.06 \mathrm{mM} \mathrm{CaCl}_{2}$ and $0.1 \%$ bovine serum albumin (BSA). When the heart was flaccid, it was rinsed with Kraft-Brühe (KB) medium (Isenberg and Klöckner 1982) for 2 min. The ventricles were cut off, chopped into small pieces and gently stirred in KB medium. Isolated cells were filtered on a $200 \mu \mathrm{m}$ filter, and then instantly homogenized in Trizol (Invitrogen Life Technologies, Carlsbad, CA, USA) to prevent loss of cells and RNA degradation, and finally kept at $-80^{\circ} \mathrm{C}$ for later remaining steps of RNA isolation.

\section{Real-time quantitative RT-PCR}

Total RNA was extracted from the previously isolated ventricular myocytes by the use of Trizol, and then purified with ethanol $75 \%$ (Sigma, St. Louis, USA). The concentration and purity of RNA was determined by measuring the absorbance at $260 \mathrm{~nm}$ with the NanoDrop Spectrophotometer ND-1000 (NanoDrop Technologies Inc, Wilmington, DE, USA). cDNA was synthesized using random primers $(250 \mathrm{ng} / \mu \mathrm{l})$, dNTP $(10 \mathrm{mmol} / \mathrm{l})$ and the SuperScript II Reverse Transcriptase kit (Invitrogen). Realtime PCR was conducted using the 7500 Real Time PCR System and the Sybr Green PCR Master Mix (Applied Biosystems, Foster City, CA, USA). To confirm the specificity of the amplified products, melting curves were performed at the end of the amplification. The amount of PCR products, calculated in reference to the individual calibration curves, were then normalized to that of either 
Table 1. SBP as well as plasma BNP and TGF- $\beta 1$ levels in the treated and untreated $2 \mathrm{~K}-1 \mathrm{C}$ male adult rats.

\begin{tabular}{|c|c|c|c|c|c|}
\hline & $\begin{array}{l}\text { Before stenosis } \\
\qquad(n=24)\end{array}$ & $\begin{array}{l}\text { Sham } \\
(n=6)\end{array}$ & $\begin{array}{c}\text { Bos } \\
(n=6)\end{array}$ & $\begin{array}{c}\text { Cap } \\
(n=6)\end{array}$ & $\begin{array}{c}\text { Bos/Cap } \\
(n=6)\end{array}$ \\
\hline $\begin{array}{l}S B P \\
(m m H g)\end{array}$ & $115.2 \pm 2.4$ & $181.8 \pm 7.5^{*}$ & $132.1 \pm 5.5^{+}$ & $124.1 \pm 8.8^{+}$ & $116.1 \pm 6.7^{+}$ \\
\hline $\begin{array}{l}\text { Plasma BNP } \\
(n g / m l)\end{array}$ & $0.675 \pm 0.11$ & $1.96 \pm 0.05^{* *}$ & $1.47 \pm 0.02^{++}$ & $1.35 \pm 0.03^{++}$ & $1.19 \pm 0.04^{++}$ \\
\hline $\begin{array}{l}\text { Plasma TGF- } \beta 1 \\
(\mathrm{ng} / \mathrm{ml})\end{array}$ & $22.82 \pm 4.26$ & $93.22 \pm 10.74 * * *$ & $27.74 \pm 0.02^{+++}$ & $24.27 \pm 3.37^{+++}$ & $23.22 \pm 3.82^{+++}$ \\
\hline
\end{tabular}

SBP: systolic blood pressure, BNP: brain natriuretic peptide, TGF- $\beta 1$ : transforming growth factor beta 1. Bos: bosentan, Cap: captopril, Bos/Cap: bosentan and captopril. ${ }^{*} p<0.001,{ }^{* *} p<0.05$ and ${ }^{* * *} p<0.005$ Sham $v s$ Before stenosis; ${ }^{+} p<0.001,{ }^{++} p<0.05$ and ${ }^{+++} p<0.005$ Treated $v s$ Sham. Data are presented as mean \pm S.E.M. n: number of animals.

TATA Binding Protein (TBP) or $\beta$-actin (ACTB), determined in the same mRNA sample. In addition, 'no RT' control reactions were performed omitting the reverse transcriptase to confirm the absence of contaminating genomic DNA. The following primers were used: BNP sense 5'-AAGTCCTAGCCAGTCTCCAGAACA-3' and antisense 5'-AGCTCCAGCAGCTTCTGCAT-3'; $\alpha$-MHC sense 5 '-CTTCTGCTGATACCGGTGACAG-3' and antisense 5'-TGAGCCTTTCTTCTTGCCTCC-3'; $\beta$-MHC sense 5'-CCTCGCAATATCAAGGGAAA-3' and antisense 5'-TACAGGTGCATCAGCTCCAG-3'; ACTB sense 5'-CGTGAAAAGATGACCCAGATCA-3' and antisense 5'-TGGATGGCTACGTACATGGC-3'; TBP sense 5'-CCACACCAGCCTCTGAGAGC-3' and antisense 5'-ATACAATATTTTGGAGCTGTGGTACAA-3'.

Renal tissue preparation for histopathology

Following the sacrifice, the right kidneys were also excised: the renal veins were cut, and kidneys were perfused with ice-cold Tyrode solution until all blood was removed, then decapsulated, cut into half through a midsagittal plane and fixed with $10 \%$ formalin solution. The formalin-fixed tissue was embedded in paraffin, and sections of $4 \mu \mathrm{m}$ thickness were cut. Paraffin-embedded sections of the kidneys were stained with either hematoxylin and eosin or Sirius red for histopathological evaluation. After staining, the sections were rinsed in distilled water, dehydrated in ethanol/water baths with decreasing water content, and finally rinsed in xylene before being mounted with a permanent mounting medium. Gross examination and histological sections were interpreted by two independent pathologists in a blinded fashion, without knowledge as to how the animals were treated. Eight sections were analyzed for each rat in the four operated groups.

\section{Statistical analysis}

Statistical analysis was performed by means of the one-way ANOVA for repeated measurements. The Mauchly's sphericity test was used to evaluate if the assumption of sphericity has been violated, then correction was performed by the Greenhouse-Geisser test. To explain the exact difference between group means, the post hoc Bonferroni test was applied.

The relationships among the changes in MA, cardiac mass, plasma BNP and $\beta$-MHC and BNP mRNA levels, before and after treatments were assessed by Spearman's correlation coefficient. $p<0.05$ values were considered to be statistically significant. All values are means \pm S.E.M.

\section{Results}

Systolic blood pressure, plasma BNP and TGF- $\beta 1$ levels SBP was significantly increased in Sham group as compared to that measured in these same rats before applying the stenosis $(181.8 \pm 7.5$ vs. $115.2 \pm 2.4 \mathrm{~mm} \mathrm{Hg}$, $\mathrm{p}<0.001$ ) (Table 1). SBP values obtained in the Bos $(132.1 \pm 5.5 \mathrm{~mm} \mathrm{Hg})$, Cap $(124.1 \pm 8.8 \mathrm{~mm} \mathrm{Hg})$ and Bos/Cap (116.1 $\pm 6.7 \mathrm{~mm} \mathrm{Hg}$ ) groups were significantly lower $(\mathrm{p}<0.001)$ than in the Sham group (Table 1), with no significant differences with the normal values before stenosis.

As shown in Table 1, mean plasma BNP and TGF- $\beta 1$ levels increased in Sham group as compared to the normal values before stenosis (BNP: $1.96 \pm 0.05$ vs $0.675 \pm 0.11 \mathrm{ng} / \mathrm{ml}, \quad \mathrm{p}<0.05$; TGF- $\beta 1: 93.22 \pm 10.74$ vs $22.82 \pm 4.26 \mathrm{ng} / \mathrm{ml}, \mathrm{p}<0.005)$. Significant decrease of BNP were noted under bosentan $(1.47 \pm 0.02 \mathrm{ng} / \mathrm{ml})$, captopril $(1.35 \pm 0.03 \mathrm{ng} / \mathrm{ml}) \quad$ or bosentan/captopril $\quad(1.19 \pm 0.04$ $\mathrm{ng} / \mathrm{ml})$ treatments $(\mathrm{p}<0.05)$. Furthermore, treatment with 
a

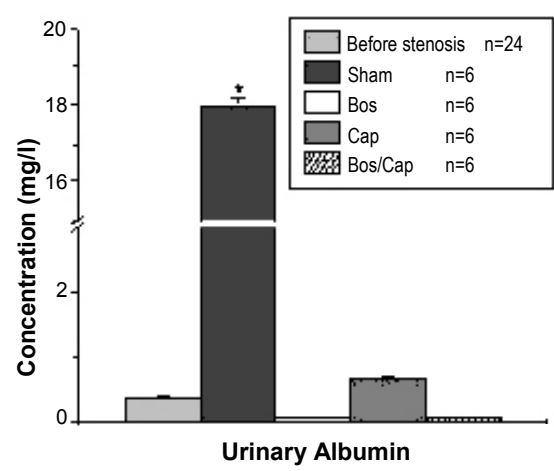

b

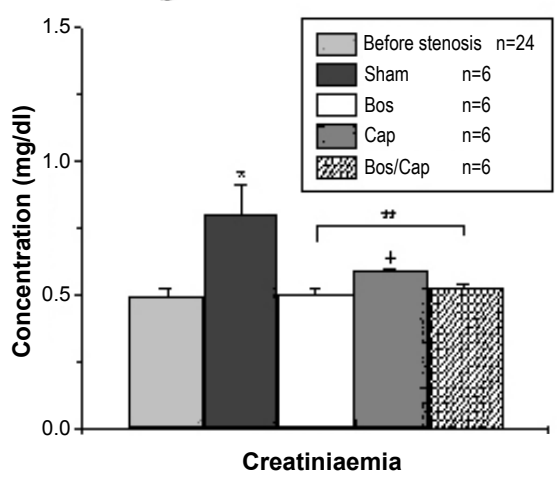

Fig. 1. Urinary albumin level and creatinine levels in the $2 \mathrm{~K}-1 \mathrm{C}$ male adult rats, under or without treatment. Bos: bosentan, Cap: captopril, Bos/Cap: bosentan and captopril. a) ${ }^{*} p<0.001$ vs Before stenosis; b) $* * p<0.05$ vs Sham, ${ }^{+} p<0.05$ vs Before stenosis. Data are presented as mean \pm S.E.M. n: number of animals.

Table 2. Cardiac mass in the treated and untreated $2 \mathrm{~K}-1 \mathrm{C}$ male adult rats.

\begin{tabular}{|c|c|c|c|c|c|}
\hline & $\begin{array}{l}\text { Control } \\
(n=24)\end{array}$ & $\begin{array}{l}\text { Sham } \\
(n=6)\end{array}$ & $\begin{array}{c}\text { Bos } \\
(n=6)\end{array}$ & $\begin{array}{l}\text { Cap } \\
(n=6)\end{array}$ & $\begin{array}{c}\text { Bos/Cap } \\
(n=6)\end{array}$ \\
\hline $\begin{array}{l}\text { Body weight } \\
(g)\end{array}$ & $234.4 \pm 17.2$ & $240.2 \pm 15.1$ & $251.5 \pm 20.3$ & $237.8 \pm 19.8$ & $245.3 \pm 16.4$ \\
\hline $\begin{array}{l}\text { Heart weight } \\
(\mathrm{mg})\end{array}$ & $860.25 \pm 49.12$ & $1258.65 \pm 103.1^{+}$ & $1094.03 \pm 98.73 *$ & $1001.14 \pm 90.24^{*}$ & $986.11 \pm 78.46^{*}$ \\
\hline \multicolumn{6}{|l|}{ Heart weight/ } \\
\hline $\begin{array}{l}\text { body weight ratio } \\
(\mathrm{mg} / \mathrm{g})\end{array}$ & $3.67 \pm 0.06$ & $5.24 \pm 0.17^{++}$ & $4.35 \pm 0.15^{*}$ & $4.21 \pm 0.09 *$ & $4.02 \pm 0.04 *$ \\
\hline
\end{tabular}

Bos: bosentan, Cap: captopril, Bos/Cap: bosentan and captorpil. ${ }^{*} p<0.05$ Treated vs Sham, ${ }^{+} p<0.05$ and ${ }^{++} p<0.005$ Sham $v s$ Control. Data are presented as mean \pm S.E.M. n: number of animals.

bosentan, captopril and their combination significantly decreased plasma TGF- $\beta 1$ levels $\quad(27.74 \pm 0.02$; $24.27 \pm 3.37$ and $23.22 \pm 3.82 \mathrm{ng} / \mathrm{ml}$ respectively, $\mathrm{p}<0.005$ ) and there were no significant differences with the normal baseline before stenosis.

\section{Urinary albumin and plasma creatinine levels}

As shown in Figure 1, rats developed MA after banding the right renal artery $(17.99 \pm 0.2$ vs $0.36 \pm 0.01$ $\mathrm{mg} / \mathrm{l}, \mathrm{p}<0.001$ ), while the low urinary albumin levels observed among groups under treatment with bosentan $(<0.07 \pm 0.01 \mathrm{mg} / \mathrm{l})$, captopril $(0.67 \pm 0.02 \mathrm{mg} / \mathrm{l})$ and the combination of both drugs $(<0.07 \pm 0.01 \mathrm{mg} / \mathrm{l})$, indicate the absence of MA.

A concomitant elevation of plasma creatinine was observed after applying the stenosis $(0.8 \pm 0.11$ vs $0.49 \pm 0.04 \mathrm{mg} / \mathrm{dl}, \mathrm{p}<0.001$; Fig. 1). Creatinine levels obtained under the treatments with bosentan $(0.5 \pm 0.03$ $\mathrm{mg} / \mathrm{dl})$, captopril $(0.59 \pm 0.003 \mathrm{mg} / \mathrm{dl})$ or bosentan/ captopril $(0.53 \pm 0.009 \mathrm{mg} / \mathrm{dl})$ were significantly lower $(p<0.05)$ than in the Sham group $(0.49 \pm 0.04 \mathrm{mg} / \mathrm{dl})$
(Fig. 1). The administration of captopril alone caused a predictable elevation of plasma creatinine compared to the normal value $(\mathrm{p}<0.05)$.

BNP, a-MHC, $\beta$-MHC gene expression and cardiac mass

As shown in Figure 2, the administration of bosentan, captopril and their combination resulted in a significant decrease of BNP expression as compared to untreated rats $(219 \pm 7,194 \pm 17$ and $187 \pm 14$ vs. $347 \pm 31 \%$, $\mathrm{p}<0.005)$. This decrease in BNP gene expression under ERB and/or ACEI treatments was accompanied by an increase in $\alpha$-MHC gene expression. In fact, $\alpha$-MHC expression increased under bosentan, captopril and the combination of both $(187 \pm 6,201 \pm 11$ and $219 \pm 18$ vs. $68 \pm 3 \%, \mathrm{p}<0.005)$. On the other hand, a significant decrease in $\beta$-MHC expression occurred under treatments ( $191 \pm 16,180 \pm 5$ and $141 \pm 13$ vs. $364 \pm 8 \%, \mathrm{p}<0.005)$. A significant increase in cardiac mass was noted in the sham group compared to control rats $(1258.65 \pm 103.1$ vs. $860.25 \pm 49.12 \mathrm{mg}, \mathrm{p}<0.05$ ) (Table 2). Treatment with the non-selective ERB and/or ACEI decreased cardiac mass 


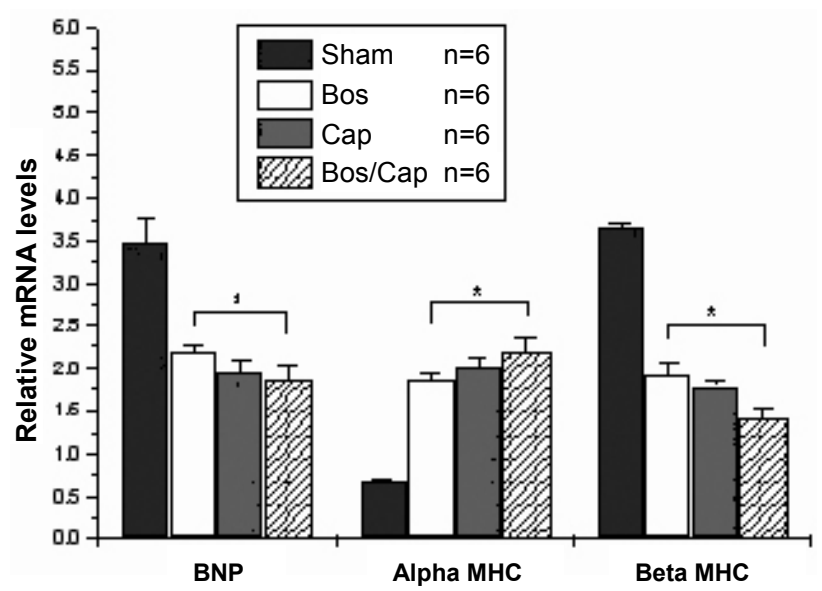

Fig. 2. BNP, alpha- and beta-MHC mRNA levels in the ventricular myocytes isolated from the hearts of the $2 \mathrm{~K}-1 \mathrm{C}$ male adult rats. Bos: bosentan, Cap: captopril, Bos/Cap: bosentan and captopril, BNP: brain natriuretic peptide, MHC: myosin heavy chain. $* p<0.005$ vs Sham. Data are presented as mean \pm S.E.M. $\mathrm{n}$ : number of animals.

$(1094.03 \pm 98.73,1001.14 \pm 90.24$ and $986.11 \pm 78.46$ vs. $1258.65 \pm 103.1 \mathrm{mg}, \mathrm{p}<0.05)$ (Table 2).

Correlation of changes in MA with changes in hypertrophy markers

After 8 weeks, there was no significant difference in body weight between the different groups (Control unoperated rats: $234.4 \pm 17.2$, Sham: $240.2 \pm 15.1$, Bos: 251.5 \pm 20.3 , Cap: $237.8 \pm 19.8$ and Bos/Cap: $245.3 \pm 16.4 \mathrm{~g}$ ) (Table 2). However, the heart weight/body weight ratio was significantly higher in the Sham group as compared to the baseline values of the control unoperated rats $(5.24 \pm 0.17$ vs $3.67 \pm 0.06 \mathrm{mg} / \mathrm{g}, \mathrm{p}<0.005)$, suggesting the development of cardiac hypertrophy in $2 \mathrm{~K}-1 \mathrm{C}$ rats of the sham group. Significant decreases, as compared to Sham rats, in heart weight/body weight ratio were noted under treatments $(4.35 \pm 0.15,4.21 \pm 0.09$ and $4.02 \pm 0.04 \mathrm{mg} / \mathrm{g}, \mathrm{p}<0.05)$.

The mean value of all MA data of each rat, correlated with the values of BNP, $\beta$-MHC mRNA levels or heart weight/body weight ratio. Table 3 shows that there was a significant positive correlation between MA and cardiac mass, BNP and $\beta$-MHC mRNA levels.

\section{Histological analysis}

Following renal artery stenosis the kidney sections from sham rats showed acute tubular necrosis in all cases and tubule cells had detached from basement membrane. Exfoliated tubular cells formed cylinders within the dilated tubular lumens (Fig. 3e) and interstitial inflammatory cells (mononuclear cells) also appeared
Table 3. Correlation of microalbuminuria with cardiac mass, BNP and $\beta$-MHC mRNA levels in $2 \mathrm{~K}-1 \mathrm{C}$ rats before and after treatments.

\begin{tabular}{|c|c|c|}
\hline & \multicolumn{2}{|c|}{ MA $(m g / d l) ~(n=24)$} \\
\hline & $r$ & $P$ value \\
\hline $\begin{array}{l}\text { Heart weight/body weight } \\
\text { ratio }(m g / g)(n=24)\end{array}$ & 0.90 & 0.05 \\
\hline$B N P m R N A(n=24)$ & 0.87 & 0.05 \\
\hline$B-M H C m R N A(n=24)$ & 0.93 & 0.05 \\
\hline
\end{tabular}

MA: microalbuminuria, BNP: brain natriuretic peptide, $\beta$-MHC: beta myosin heavy chain. $p$ values were assessed by the Spearman's correlation coefficient $r . \mathrm{n}$ - number of animals.

(Fig. 3f). Staining with Sirius red also showed elevated levels of interstitial collagen deposition in all examined sections (Fig. 4e). Rats treated with ACEI, ERB or their combination showed a normal parenchyma in $75 \%$, $62.5 \%$ and $87.5 \%$ of kidney sections (Figs 3b-d). Glomerulotubular sections were clear with no signs of tubular cell vacuolization or necrosis. The interstitial space was very little visible with no inflammatory infiltration. Marked reductions of interstitial collagen were noticed with Sirius red staining in $75 \%, 75 \%$ and $87.5 \%$ of the kidney histological sections of the rats under ACEI, ERB and ACEI/ERB treatment, respectively, indicating the regression of fibrosis (Figs $4 b-d)$.

\section{Discussion}

In this study, we were able to demonstrate the existence of a possible link between MA evolution, a major risk factor of the cardiorenal syndrome (CRS), and BNP, a marker of cardiac hypertrophy.

After applying unilateral renal artery stenosis, the rats without any treatment developed hypertension (Table 1). In fact, renal artery stenosis causes a glomerular filtration rate (GFR) reduction and thus setting off the RAAS cascade in order to maintain a constant GFR by efferent renal artery constriction. Bosentan significantly decreased SBP which is consistent with previous findings of Krum et al. (1998). Nevertheless, several authors have reported no change in blood pressure using different selective and non-selective ET-1 antagonists in 2K-1C hypertension (Ehmke et al. 1999, Hocher et al. 1999), but most of these studies were carried out during the early phase in the development of hypertension. Others found attenuation of the rise in 

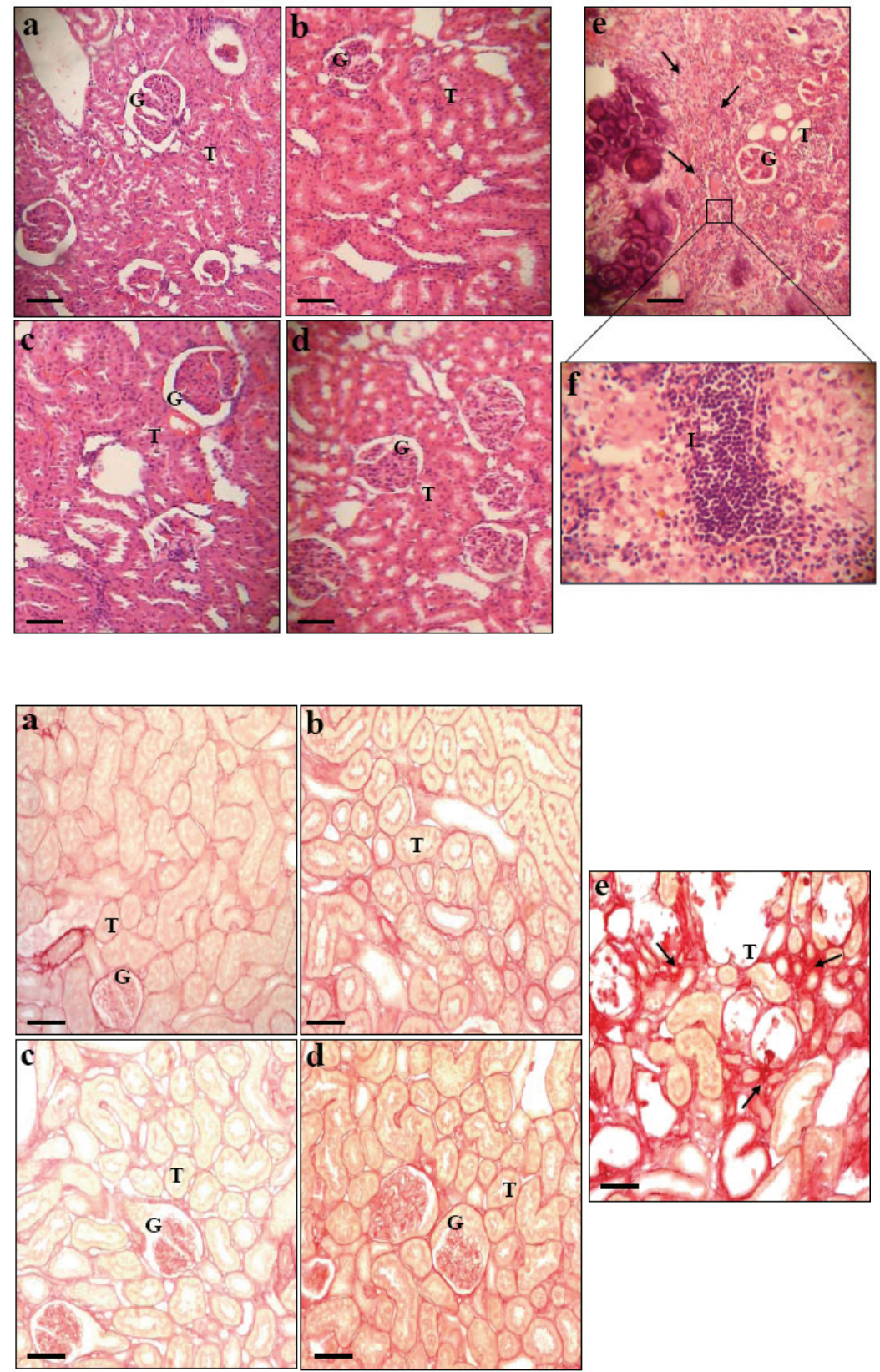

Fig. 3. Hematoxylin and eosin staining of the $2 \mathrm{~K}-1 \mathrm{C}$ male adult rats kidney sections, under or without treatment. a) control, b) bosentan, c) captopril, d) bosentan/captopril, e) sham. G: glomerule, T: tubule, L: lymphocytes. Arrows in $f)$ show the interstitial inflammatory outbreaks. Magnification: x200 in (a-e) and x400 in (f). Scale bars: $50 \mu \mathrm{m}$. blood pressure following treatment with selective ET-A antagonists, even at 2 days after clipping (Schricker et al. 1995). Captopril administration alone was more effective than the bosentan in reducing BP; in fact, ACEI remain the first line of renovascular hypertension treatment (Ruggenenti et al. 2006). Additive hemodynamic effects of combined non-selective ERB and ACEI therapy were noted in our Bos/Cap group as previously reported by Teerlink et al. (1994).

BNP is the leading marker of ventricular hypertrophy (Scardovi 2004). MA, a marker of systemic inflammation and endothelial dysfunction (Stehouwer 2004) is associated with a high CVD risk in patients with diabetes (Dries et al. 2001), and hypertension (Wachtell et
Fig. 4. Sirius red collagen staining of the $2 \mathrm{~K}-1 \mathrm{C}$ male adult rats kidney sections, under or without treatment. a) control, b) bosentan, c) captopril, d) bosentan/captopril, e) sham. G: glomerule, T: tubule. Arrows in e) show the interstitial collagen deposite. Magnification: x200. Scale bars: $50 \mu \mathrm{m}$. al. 2003), as well as in seemingly healthy individuals (Hillege et al. 2002). The link between MA and hypertension is mediated by inflammation (Kalra et al. 2005, Wang et al. 2005). Moreover, MA is also a risk factor contributing to the proximal renal tubule inflammation resulting in renal fibrosis (Shankland 2006). MA is considered not only a predictor of CVD, fibrosis and CKD, but also a therapeutic target (Ibsen et al. 2005).

The predictive effect of albuminuria in CVD extends its limits to the general population where even low levels of urinary albumin, below the MA threshold, predict the development of a composite of cardiovascular events, including HF, as showed by Arnlov et al. (2005) in middle-aged nonhypertensive and nondiabetic individuals. 
In our study, high $\mathrm{BP}$ in $2 \mathrm{~K}-1 \mathrm{C}$ rats was accompanied by MA development and increased BNP levels (Fig. 1, Table 1). Bosentan and/or captopril administration eliminated MA and reduced plasma BNP which was accompanied by the regression of cardiac mass (Table 2) suggesting the regression of cardiac hypertrophy under the non-selective ERB and/or ACEI treatment. This parallel evolution of the two parameters evokes their strong positive correlation (Table 3) and suggests a cardioprotective role of MA-lowering. In a recent study (Uno et al. 2008), a correlation between blood pressure control, MA and BNP was found, but cardiac hypertrophy was not evaluated, and thus the relationship between MA and cardiac hypertrophy remains vague.

The relationship between MA and hypertension leading to cardiac hypertrophy and HF is very complex. Previous cross-sectional studies indicate that MA may be a feature of hypertension and a marker of target-organ damage (Cirillo et al. 1998), whereas others showed that urinary albumin excretion predicts blood pressure progression in nondiabetic, nonhypertensive individuals incrementally over established risk factors and at levels well below the conventional threshold for MA (Wang et al. 2005). Since the present findings focused on cardiac hypertrophy, in the initial stages leading to HF, cardioprotective antihypertensive treatments led to a decrease in SBP parallel to the decline in MA. However, other large-scale randomized clinical trials showed that albuminuria is a risk predictor of heart failure irrespective of antihypertensive treatment (Arnold et al. 2003), which validates our conclusion on the cardioprotective role of MA-lowering in the initial stages of the disease, with MA being the most important predictor of cardiac hypertrophy and eventually HF.

Angiotensin II (AngII) and endothelin-1 (ET-1) stimulate TGF- $\beta 1$ gene expression (Sung et al. 1994). AngII can activate collagen I gene in aorta and renal cortex in vivo by a mechanism requiring participation and/or cooperation of ET-1 and TGF- $\beta 1$ (Fakhouri et al. 2001). ACE inhibition and endothelin receptor ET-A/B blockade result in a decline of cardiac and renal fibrosis (Kuwahara et al. 1999). Similarly, our study shows first an increase in TGF- $\beta 1$ levels after clipping the renal artery parallel to the increase of interstitial fibrosis and tubular injury; after treatment with ACEI and/or non-selective ERB, TGF- $\beta 1$ level decreased with an improvement of renal histology (Table 1, Figs 3 and 4). Likewise, we were able to demonstrate a parallel evolution between TGF- $\beta 1$, BNP, $\mathrm{MA}$ and high BP, as well as reno- and cardioprotective effects of MA-lowering, which were manifested by TGF$\beta 1$ decrease, leading thus to a reduced fibrogenesis.

A significant creatinine increase was noted after stenosis, showing a renal function disruption parallel to the changes in BNP and MA. Creatinine decrease occurred after treatment with bosentan and bosentan/captopril, justifying the renoprotective role of MA-lowering (Fig. 1). Creatinine elevation, as compared to controls, observed under ACEI treatment was already expected and demonstrated by several authors (Textor and Wilcox 2001).

The significant decrease in heart weight/body weight ratio, BNP and $\beta$-MHC gene expression under the non-selective ERB, through its ET-A receptor blockade (Bianciotti and De Bold 2001) and/or ACEI (Fig. 2) was correlated with MA lowering ( $r=0.90, r=0.87$ and $r=0.93$, respectively, $p<0.05)$. These results justify the cardioprotective role of MA-lowering, manifested by the decline of gene expression of BNP and $\beta$-MHC, markers of cardiac hypertrophy. Simultaneous increase in $\alpha$-MHC expression supports the last obtained result for the cardioprotective role of MA-lowering; $\alpha$-MHC being the myosin isoform with the more pronounced ATPase activity (Lowes et al. 1997).

In conclusion, we found an existing link between MA evolution and ventricular hypertrophy in the CRS. Moreover, MA-lowering therapy has both renoprotective effect as evaluated by microalbuminuria and creatinine levels, and cardioprotective effect as evaluated by cardiac mass, plasma BNP and $\alpha-, \beta-M H C$ and BNP mRNA levels.

\section{Conflict of Interest}

There is no conflict of interest.

\section{Acknowledgements}

This work was supported by the Research Council of the Saint Joseph University - Faculty of Medicine.

\section{References}

ARNLOV J, EVANS JC, MEIGS JB, WANG TJ, FOX CS, LEVY D, BENJAMIN EJ, D'AGOSTINO RB, VASAN RS: Low-grade albuminuria and incidence of cardiovascular disease events in nonhypertensive and nondiabetic individuals: the Framingham Heart Study. Circulation 112: 969-975, 2005. 
ARNOLD JM, YUSUF S, YOUNG J, MATHEW J, JOHNSTONE D, AVEZUM A, LONN E, POGUE J, BOSCH J, HOPE Investigators: Prevention of heart failure in patients in the Heart Outcomes Prevention Evaluation (HOPE) Study. Circulation 107: 1284-1290, 2003.

BIANCIOTTI LG, DE BOLD AJ: Modulation of cardiac natriuretic peptide gene expression following endothelin type A receptor blockade in renovascular hypertension. Cardiovasc Res 49: 808-816, 2001.

BRENNER BM, COOPER ME, DE ZEEUW D, KEANE WF, MITCH WE, PARVING HH, REMUZZI G, SNAPINN SM, ZHANG Z, SHAHINFAR S, RENAAL Study Investigators: Effects of losartan on renal and cardiovascular outcomes in patients with type 2 diabetes and nephropathy. N Engl J Med 345: 861-869, 2001.

CIRILLO M, SENIGALLIESI L, LAURENZI M, ALFIERI R, STAMLER J, STAMLER R, PANARELLI W, DE SANTO NG: Microalbuminuria in nondiabetic adults: relation of blood pressure, body mass index, plasma cholesterol levels, and smoking: the Gubbio Population Study. Arch Intern Med 158: 1933-1939, 1998.

DRIES DL, SWEITZER NK, DRAZNER MH, STEVENSON LW, GERSH BJ: Prognostic impact of diabetes mellitus in patients with heart failure according to the etiology of left ventricular systolic dysfunction. $J$ Am Coll Cardiol 38: 421-428, 2001.

EHMKE H, FAULHABER J, MUNTER K, KIRCHENGAST M, WIESNER RJ: Chronic ETA receptor blockade attenuates cardiac hypertrophy independently of blood pressure effects in renovascular hypertensive rats. Hypertension 33: 954-960, 1999.

FAKHOURI F, PLACIER S, ARDAILLOU R, DUSSAULE JC, CHATZIANTONIOU C: Angiotensin II activates collagen type I gene in the renal cortex and aorta of transgenic mice through interaction with endothelin and TGF-ß. J Am Soc Nephrol 12: 2701-2710, 2001.

FARES N, GOMEZ JP, POTREAU D: T-type calcium current is expressed in dedifferentiated adult rat ventricular cells in primary culture. C R Acad Sci III 319: 569-576, 1996.

HILLEGE HL, FIDLER V, DIERCKS GF, VAN GILST WH, DE ZEEUW D, VAN VELDHUISEN DJ, GANS RO, JANSSEN WM, GROBBEE DE, DE JONG PE, Prevention of Renal and Vascular End Stage Disease (PREVEND) Study Group: Urinary albumin excretion predicts cardiovascular and noncardiovascular mortality in general population. Circulation 106: 1777-1782, 2002.

HOCHER B, GEORGE I, REBSTOCK J, BAUCH A, SCHWARZ A, NEUMAYER HH, BAUER C: Endothelin systemdependent cardiac remodelling in renovascular hypertension. Hypertension 33: 816-822, 1999.

IBSEN H, OLSEN MH, WACHTELL K, BORCH-JOHNSEN K, LINDHOLM LH, MOGENSEN CE, DAHLOF B, DEVEREUX RB, DE FAIRE U, FYHRQUIST F, JULIUS S, KJELDSEN SE, LEDERBALLE-PEDERSEN O, NIEMINEN MS, OMVIK P, OPARIL S, WAN Y: Reduction in albuminuria translates to reduction in cardiovascular events in hypertensive patients: Losartan Intervention for Endpoint Reduction in Hypertension Study. Hypertension 45: 198-202, 2005.

ISENBERG G, KLOCKNER U: Calcium currents of isolated bovine ventricular myocytes are fast and of large amplitude. Pflügers Arch 395: 30-41, 1982.

KALRA V, MAHAJAN S, AGARWAL SK, TIWARI SC: Cardiorenal disease: a clinical intersection. Int Urol Nephrol 37: 175-184, 2005.

KEITH DS, NICHOLS GA, GULLION CM, BROWN JB, SMITH DH: Longitudinal follow-up and outcomes among a population with chronic kidney in a large managed care organization. Arch Intern Med 164: 659-663, 2004.

KRUM H, VISKOPER RJ, LACOURCIERE Y, BUDDE M, CHARLON V, for The Bosentan Hypertension Investigators: The effect of an endothelin-receptor antagonist, bosentan, on blood pressure in patients with essential hypertension. $N$ Eng $J$ Med 338: 784-791, 1998.

KUBOTA Y, UMEGAKI K, KAGOTA S, TANAKA N, NAKAMURA K, KUNITOMO M, SHINOZUKA K: Evaluation of blood pressure measured by tail-cuff methods (without heating) in spontaneously hypertensive rats. Biol Pharm Bull 29: 1756-1758, 2006.

KUWAHARA F, KAI H, NAGATA T, SHIBATA R, NIIYAMA H, IMAIZUMI T: Inhibition of TGF $\beta$ prevents cardiac fibrosis and diastolic dysfunction in hypertensive rats. Int Soc Heart Res Annu Meet Jpn Sect Program Abstr 16: $45,1999$. 
LOWES BD, MINOBE W, ABRAHAM WT, RIZEQ MN, BOHLMEYER TJ, QUAIFE RA, RODEN RL, DUTCHER DL, ROBERTSON AD, VOELKEL NF, BADESCH DB, GROVES BM, GILBERT EM, BRISTOW MR: Changes in gene expression in the intact human heart. Downregulation of alpha-myosin heavy chain in hypertrophied, failing ventricular myocardium. J Clin Invest 100: 2315-2324, 1997.

MCALISTER FA, EZEKOWITZ J, TONELLI M, ARMSTRONG PW: Renal insufficiency and heart failure: prognostic and therapeutic implications from a prospective cohort study. Circulation 109: 1004-1009, 2004.

MCCULLOUGH PA: Cardiorenal intersection: Crossroads to the future. Arq Bras Cardiol 88: 100-108, 2007.

MCCULLOUGH PA: Cardiorenal risk: an important clinical intersection. Rev Cardiovasc Med 3: 71-76, 2002.

RONCO C, HOUSE AA, HAAPIO M: Cardiorenal syndrome: refining the definition of a complex symbiosis gone wrong. Intensive Care Med 34: 957-962, 2008.

RUGGENENTI P, PERNA A, GANEVA M, ENE-IORDACHE B, REMUZZI G, BENEDICT STUDY GROUP: Impact of blood pressure control and angiotensin-converting enzyme inhibitor therapy on new on-set microalbuminuria in type 2 diabetes: a post hoc analysis of the BENEDICT trial. J Am Soc Nephrol 17: 3472-3481, 2006.

SCARDOVI AB: Clinical applications of brain natriuretic peptide testing. Ital Heart J 5 (Suppl): 343-356, 2004.

SCHRICKER K, SCHOLZ H, HAMANN M, CLOZEL M, KRAMER BK, KURTZ A: Role of endogenous endothelins in the rennin system of normal and two-kidney, one clip rats. Hypertension 25: 1025-1029, 1995.

SCHRIER RW: Role of diminished renal function in cardiovascular mortality: marker or pathogenetic factor? J Am Coll Cardiol 47: 1-8, 2006.

SHANKLAND SJ: The podocyte's response to injury: role in proteinuria and glomerulosclerosis. Kidney Int 69: 21312147, 2006.

STEHOUWER CD: Endothelial dysfunction in diabetic nephropathy: State of the art and potential significance for non-diabetic renal disease. Nephrol Dial Transplant 19: 778-781, 2004.

SUNG CP, ARLETH AJ, STORER L, OHLSTEIN EH: Angiotensin type I receptors mediate smooth muscle proliferation and endothelin biosynthesis in rat vascular smooth muscle. J Pharmacol Exp Ther 271: 429-437, 1994.

SWISLOCKI ALM, KINNEY LAPIER TL, KHUU DT, FANN KY, TAIT M, RODNICK KJ: Metabolic, hemodynamic, and cardiac effects of captopril in young, spontaneously hypertensive rats. Am J Hypertens 12: 581-589, 1999.

TEERLINK JR, LOFFLER BM, HESS P, MAIRE JP, CLOZEL M, CLOZEL JP: Role of endothelin in the maintenance of blood pressure in conscious rats with chronic heart failure: acute effects of the endothelin receptor antagonist Ro 47-0203 (bosentan). Circulation 90: 2510-2518, 1994.

TEXTOR SC, WILCOX CS: Renal artery stenosis: a common, treatable cause of renal failure? Annu Rev Med 52: 421-442, 2001.

UNITED STATES RENAL DATA SYSTEM. USRDS 2008, Annual Data Report. Bethesda MD., 2008. National Institute of Health, National Institute of Diabetes and Digestive and Kidney Diseases.

UNO H, ISHIKAWA J, HOSHIDE S, KABUTOYA T, ISHIKAWA S, SHIMADA K, KARIO K: Effects of strict blood pressure control by a long-acting calcium channel blocker on brain natriuretic peptide and urinary albumin excretion rate in Japanese hypertensive patients. Hypertens Res 31: 887-896, 2008.

VAN DOKKUM RP, EIJKELKAMP WB, KLUPPEL AC, HENNING RH, VAN GOOR H, CITGEZ M, WINDT WA, VAN VELDHUISEN DJ, DE GRAEFF PA, DE ZEEUW D: Myocardial infarction enhances progressive renal damage in an experimental model for cardio-renal interaction. $J$ Am Soc Nephrol 15: 3103-3110, 2004.

WACHTELL K, OLSEN MH, DAHLOF B, DEVEREUX RB, KJELDSEN SE, NIEMINEN MS, OKIN PM, PAPADEMETRIOU V, MOGENSEN CE, BORCH-JOHNSEN K, IBSEN H: Microalbuminuria in hypertensive patients with electrocardiographic left ventricular hypertrophy: the LIFE study. J Hypertens 20: 405-412, 2002.

WACHTELL K, IBSEN H, OLSEN MH, BORCH-JOHNSEN K, LINDHOLM LH, MOGENSEN CE, DAHLOF B, DEVEREUX RB, BEEVERS G, DE FAIRE U, FYHRQUIST F, JULIUS S, KJELDSEN SE, KRISTIANSON K, LEDERBALLE-PEDERSEN O, NIEMINEN MS, OKIN PM, OMVIK P, OPARIL S, WEDEL H, SNAPINN SM, AURUP P: Albuminuria and cardiovascular risk in hypertensive patients with left ventricular hypertrophy: The Life Study. Ann Intern Med 139: 901-906, 2003.

WANG TJ, EVANS JC, MEIGS JB, RIFAI N, FOX CS, D’AGOSTINO RB, LEVY D, VASAN RS: Low-grade albuminuria and risks of hypertension and high blood pressure. Circulation 111: 1370-1376, 2005. 